\title{
La resolución de conflictos en las cooperativas: Análisis del caso vasco
}

\author{
Naiara Arriola Etxaniz, Bárbara Díez Viadero, \\ Ainara Gutiérrez Berezo \\ Universidad de Deusto
}

\section{Introducción}

En este trabajo intentaremos exponer el modo en que se resuelven los conflictos en las sociedades cooperativas centrándonos para este análisis en la Ley de Cooperativas de Euskadi, de 24 de junio de 1993, reformada recientemente por la Ley 1/2000, de 29 de junio, de modificación de la Ley de Cooperativas del País Vasco.

Antes de iniciar con esta exposición nos parece necesario comentar brevemente los aspectos más importantes que definen a una sociedad cooperativa. En base a conseguir este objetivo enumeraremos algunas de las conclusiones de la tesis de «El Retorno Cooperativo» de Joaquín Mateo Blanco.

Las cooperativas son sociedades que nacen a mediados del siglo XIX, principalmente en Gran Bretaña y Francia. Desde sus orígenes estas sociedades estaban emparentadas con el movimiento obrero sindical y se presentaron unidas con el mutualismo y la previsión social.

Las sociedades cooperativas actuales se rigen por los siguientes principios: en primer lugar, tienen un carácter democrático personal. La soberanía jurídica se encuentra en las personas y no en las cuotas de capital social que cada una de ellas haya entregado a la cooperativa. Este principio lo encontramos así recogido, por ejemplo, en el artículo 35.1 de la Ley de Cooperativas de Euskadi de 1993. En segundo lugar, en las sociedades cooperativas el capital no atribuye derechos económicos. Esto significa que en el reparto de beneficios en este tipo de sociedades está totalmente prohibido el prorrateo capitalista y este 
reparto se efectuará en base a criterios tales como la proporción a actividad o servicios prestados a la sociedad, como determina el artículo 67.4 de la Ley de Cooperativas de Euskadi.

Con el transcurso del tiempo y con la aparición de nuevas fórmulas de sociedades cooperativas se va desplazando su carácter meramente asociativo y de defensa de intereses de clase hacia una globalización mayor y una creciente importancia de los aspectos económicos. Eso hace que sea considerada como parte integrante del Derecho mercantil, si bien no dejan de apreciarse en ellas notas diferenciales. La razón de este diferencia se suele basar en el contenido de los principios cooperativos que ya hemos comentado con anterioridad.

Tras este comentario podríamos definir a la sociedad cooperativa como aquella "asociación autónoma de personas que se han unido de forma voluntaria para satisfacer sus necesidades y aspiraciones económicas, sociales y culturales en común mediante una empresa de propiedad conjunta y de gestión democrática» ${ }^{1}$ y entenderemos por socio cooperativo a aquella "persona que forma parte de una cooperativa y que se caracteriza por tener los mismos derechos que todos los demás socios de las cooperativas, por no responder personalmente de las deudas sociales a no ser que los estatutos establezcan lo contrario, por tener la obligación de participar en la actividad empresarial de la cooperativa, por tener la posibilidad de percibir un interés por su aportación al capital y por no participar directamente en los posibles excedentes del balance de fin de ejercicio»².

Después de haber situado en el ámbito en el que se moverá nuestro trabajo comenzaremos a centrar el objeto de nuestro análisis. Ya que hemos conceptualizado lo que es una cooperativa y lo que supone ser socio de la misma, en cuanto a la conflictividad que surge entre ambas figuras, es decir, entre el socio y la propia sociedad cooperativa, cabe decir lo siguiente.

En la sociedad cooperativa y derivado del principio de «puerta abierta» cabe la baja voluntaria de los socios pero además puede que sea obligada si el socio perdiese los requisitos necesarios para serlo, entonces el socio sería expulsado de la cooperativa.

1 Ley 1/2000, de 29 de junio, de modificación de la Ley de Cooperativas del País Vasco. Exposición de Motivos, párrafo 3.․

2 Andersen, Arthur. Economía y negocios. Ed: Espasa. Madrid, 1998. Pág. 630. 
Atendiendo al artículo 26 de la Ley Vasca de Cooperativas el socio puede darse de baja de la sociedad en cualquier momento, cumpliendo para ello las formalidades establecidas en la ley. Seguidamente en la Ley, en su artículo 27, se determina que sin solicitud necesaria por parte del socio, éste podrá ser expulsado de la sociedad cooperativa previa audiencia del mismo cuando pierda los requisitos legales o estatutarios que le asegurasen ese estatus jurídico.

Tanto en las bajas voluntarias como en las obligatorias el socio puede recurrir esta decisión según determina el artículo 28 de la Ley Vasca de Cooperativas.

En otro nivel de gravedad, la Ley también recoge normas de disciplina social. Para poder sancionar a los socios en base a dichas normas deben estar previamente tipificadas en los Estatutos de cada sociedad en concreto. Así lo establece el artículo 29 de la Ley de 1993. La conducta también será sancionable si está tipificada en la ley.

Las sanciones que se pueden imponer a los socios serán fijadas en los Estatutos y podrán de ser de amonestación, económicas, de suspensión de derechos sociales, o de expulsión. Los Estatutos fijarán también los procedimientos sancionadores que han de seguirse en la sociedad y los recursos que corresponderán a cada tipo de procedimiento aunque la Ley Vasca de Cooperativas recoge unos contenidos mínimos obligatorios que tendrán que tener estos supuestos. En primer lugar, la facultad condenatoria es competencia de los administradores. En segundo lugar, en todo procedimiento sancionador se deberá dar audiencia al interesado para respetar con ello el artículo 24 de la Constitución Española de 1978 y que no se produzca indefensión de la persona sobre la que recaerá la sanción. En tercer lugar, en todas las sanciones por faltas graves o muy graves cabrá recurso ante el Comité de Recursos y, en su defecto, ante la Asamblea General, en un plazo máximo de 30 días desde la notificación de la sanción. En cuarto lugar, el artículo 29.3.d) de la Ley recoge que el acuerdo que establezca la sanción concreta aplicable podrá ser impugnado según el trámite procesal que establece el artículo 49 de esta Ley. Este último artículo mencionado recoge el procedimiento de impugnación de los acuerdos de los administradores y en él se establece lo siguiente. Para la impugnación de este acuerdo, entre otros que se recogen en el artículo, es necesario que sea contrario a la Ley o a los Estatutos o que el acuerdo de sanción lesione, en beneficio de uno o varios socios o de terceros, los intereses de la cooperativa. Para ello el socio tendrá un plazo de im- 
pugnación de 60 días desde que tuvo conocimiento del acuerdo y siempre que no haya transcurrido un año desde su adopción.

En cuanto a la prescripción de las sanciones: las leves prescriben al mes, las graves a los dos meses, y las muy graves a los tres meses. Este plazo de prescripción empieza a contar desde el momento en que los administradores tienen conocimiento de la comisión de la infracción y, en cualquier caso, doce meses después de haber sido cometida. Este último plazo se establece para garantizar la propia seguridad jurídica ya que «el socio no puede quedar sujeto a la amenaza de posibles sanciones por antiguas infracciones» ${ }^{3}$.

De entre las sanciones que hemos comentado que son aplicables a los socios la máxima de todas ellas es la expulsión del mismo de la sociedad. Esta sanción exige la comisión de una falta calificada como muy grave según los Estatutos de la sociedad, que se instruya un expediente al efecto y la audiencia del interesado. Contra el acuerdo que determine la expulsión del socio cabe recurso en el plazo de 30 días ante el Comité de Recursos o, en su defecto, ante la Asamblea General. Tras ser ratificado por cualquiera de estos órganos podrá ser impugnado, en el plazo de dos meses, en la vía judicial.

\section{Arbitraje, Conciliación y Mediación}

A continuación vamos a comentar otras tres formas que posibilitan la resolución de conflictos dentro de las sociedades cooperativas, éstas son el arbitraje, la mediación y la conciliación. Dejaremos fuera de nuestro análisis la vía judicial para la resolución de conflictos entre los socios y la sociedad cooperativa.

\section{El Arbitraje}

Los conflictos en las cooperativas tienen distintas formas de solucionarse. La fórmula más utilizada es la vía judicial. Así, el artículo 104 de la Ley Vasca de Cooperativas 4/1993 (24 de junio) señala que los órganos jurisdiccionales del orden social son los encargados de conocer los conflictos que surjan entre cooperativas de trabajo asociado y

3 Gadea, Enrique. Derecho de las cooperativas, Universidad de Deusto. Bilbao, 2001. Pág. 154. 
sus socios trabajadores. Los demás estarán sometidos al orden civil. A continuación, dicho artículo establece a qué se refieren esos conflictos entre las cooperativas y sus socios: percepción de anticipos laborales o prestaciones complementarias, recursos por sanciones, situaciones de suspensión y excedencias.

Sin embargo, no es ni mucho menos la única fórmula sino que hay otras que según el caso pueden ser más recomendables. Es el caso del arbitraje.

Tiene por objeto resolver todo tipo de controversias entre entidades cooperativas o entre estas y sus miembros. Aunque se asemeja a un juicio (hay quienes consideran que tiene naturaleza jurisdiccional como Antonio Muñoz Vidal) se diferencia de él en muchas cosas. Por ejemplo, no es preceptiva la intervención de abogado y procurador, no hay demandante y demandado, no se pueden adoptar medidas cautelares... Sin embrago, tienen también muchas cosas en común con el juicio ya que, por ejemplo, sí existe un Tribunal de Arbitraje Cooperativo.

Como todo el mundo sabe, una de las cosas en las que falla el procedimiento judicial es que se puede prolongar durante mucho tiempo debido entre otras cosas a que su sentencia es recurrible. En cambio, el proceso arbitral es más rápido porque carece de tantas «formalidades» y vías de impugnación. Esta rapidez contribuye a que salga más económico para ambas partes, lo que no significa que el arbitraje sea gratuito ya que no está exento de ciertos gastos.

Los laudos pueden impugnarse mediante recurso de nulidad ante el Tribunal Supremo. Dicha impugnación deberá basarse en la incongruencia del fallo o en que dicho laudo se extiende a cuestiones no cooperativas. Una vez firmes son inmediatamente ejecutivos, es decir, no hace falta que un Tribunal los homologue sino que se dedicará a hacerlo ejecutar directamente.

Por otro lado, gracias al arbitraje podemos tener mayor flexibilidad porque no tiene que estar a la estricta aplicación de las normas que no siempre pueden preverlo todo.

En definitiva, el arbitraje se presenta como una fórmula más de resolver un conflicto y, como toda forma, tiene sus ventajas y desventajas. Sin embargo, es importante tenerlo en cuenta como método alternativo al procedimiento judicial ya que sus beneficios son superiores. Además no es tan drástico, el árbitro trata de llegar a una solu- 
ción justa que satisfaga a ambas partes enfrentadas. Trata en todo momento de promover que las cooperativas arreglen sus problemas y diferencias en el ámbito interno evitando los litigios que al final terminan perjudicando al propio cooperativismo.

\section{Consejo SuPERIOR de CoOperativas de EusKadI}

Por su parte, el artículo 145 de la Ley Vasca de Cooperativas establece que el máximo órgano de promoción y difusión del cooperativismo es el Consejo Superior de Cooperativas de Euskadi, que es una entidad pública de carácter consultivo y asesor de las administraciones públicas vascas para todos los temas que afecten al cooperativismo. Entre sus funciones cabe destacar la que consiste en intervenir en las vías litigiosas que se susciten entre las cooperativas o entre éstas y sus socios por vía del arbitraje. Realizará esta función cuando las partes lo soliciten o estén obligadas a ello a tenor de sus Estatutos, su Reglamento Interno o por una cláusula compromisoria.

En todo caso, la cuestión litigiosa debe recaer sobre materias de libre disposición por las partes conforme a derecho y afectar primordialmente a la interpretación y aplicación de principios, normas, costumbres y usos de naturaleza cooperativa.

En virtud de este artículo, el Consejo Superior de Cooperativas de Euskadi viene realizando esta labor a través del Servicio de Arbitraje Cooperativo (Servicio Vasco de Resolución Extrajudicial de Conflictos en Cooperativas - Bitartu).

Bitartu carece de personalidad jurídica propia y depende jerárquicamente del Consejo Superior, sin perjuicio de las facultades y competencias que le atribuye el presente Reglamento, prestando un servicio a las sociedades cooperativas y sus socios, en lo que al arbitraje se refiere, fundamentado en las normas de derecho privado contenidas en la Ley 60/2003. De hecho, tiene su sede en el Consejo Superior de Cooperativas de Euskadi.

Por ello cree conveniente crear un nuevo Reglamento de Arbitraje Cooperativo que sirva de instrumento para realizar este servicio. Este nuevo reglamento incorpora novedades tales como: el arbitraje se resolverá en derecho salvo que las partes hayan optado expresamente por la equidad; el cómputo de plazos por días naturales; la determinación de más causas de suspensión que no necesitan acuerdo de todas las partes; la atribución a los árbitros de la potestad de deliberación 
sobre la admisión a trámite de la solicitud de arbitraje y para decidir sobre su competencia; el carácter sucesivo y no simultáneo de los escritos de alegaciones de las partes; la facultad del demandado de efectuar reconvención al contestar a la demanda; la posibilidad expresa de finalizar el procedimiento mediante acuerdo de las partes vinculante para los árbitros; la posibilidad de utilizar nuevas tecnologías en cuanto a la forma de emitir el laudo; la no protocolización notarial del laudo salvo que alguna de las partes lo solicite; la previsión de una nueva forma de impugnación del laudo, o el alcance limitado de la gratuidad del arbitraje.

En lo no previsto por este nuevo Reglamento se aplicará la Ley 60/2003, de 23 de diciembre, de Arbitraje.

\section{REGLAMENTO}

Habrá arbitraje por el Consejo Superior de Cooperativas de Euskadi cuando haya una controversia que se plantee en los siguientes supuestos:

a) Cuando las partes estén obligadas a ello a tenor de los Estatutos Sociales o Reglamento de Régimen Interno de la cooperativa.

b) Cuando exista convenio arbitral entre las partes si cualquiera de ellas se dirige a este organismo y solicita su intervención.

La sumisión al arbitraje del Consejo supone tanto la administración del arbitraje como la designación de los árbitros.

c) Cuando, surgidas discrepancias entre las partes, exista acuerdo de todas ellas para someterse al arbitraje del Consejo.

Salvo que las partes señalen expresamente que quieren someterse a un arbitraje basado en la equidad, se basará en el derecho (es una novedad).

El procedimiento arbitral se desarrollará en la sede de Bitartu o en el lugar que determinen los árbitros, debiendo ser en todo caso en la Comunidad Autónoma del País Vasco. No obstante, los árbitros podrán decidir la realización de actos fuera de dicho lugar cuando lo consideren conveniente para la resolución del arbitraje. Además se podrá realizar en cualquiera de los idiomas oficiales de Euskadi.

Las partes pueden defenderse por sí mismas o mediante otros a los que deberán otorgar expresamente un poder que les habilite a 
ello. Dicho poder se otorgará frente a notario o ante el secretario de Bitartu. También deberán señalar su domicilio para que le sean allí enviadas las comunicaciones o notificaciones que sean necesarias aunque éstas también pueden realizarse vía telemática. Ante cualquier cambio de domicilio hay que ponerlo en conocimiento.

Para poder ser árbitro hay que cumplir una serie de requisitos:

—Personas físicas que se hallen en pleno ejercicio de sus derechos civiles.

- Que no se lo impida la legislación a la que puedan estar sometidos en el ejercicio de su profesión.

- Cuando la cuestión litigiosa haya de decidirse con arreglo a Derecho, los árbitros habrán de ser abogados en ejercicio, salvo que todas las partes en el procedimiento acepten expresamente la designación por Bitartu de una persona que no cumpla ese requisito o, en su caso, acuerden lo contrario.

-El nombramiento deberá recaer en persona imparcial, que goce de independencia personal, profesional y comercial, respecto a las partes y a la cuestión litigiosa. Por ello cabe la abstención o recusación.

Las personas designadas como árbitros están obligadas a poner de manifiesto a Bitartu y a cada una de las partes las circunstancias que puedan determinar su recusación tan pronto como las conozcan. La parte que recuse a un árbitro expondrá los motivos dentro de los diez días siguientes a aquél en que tenga conocimiento de la aceptación o de cualquiera de las circunstancias que puedan dar lugar a dudas justificadas sobre su imparcialidad o independencia. A menos que el árbitro recusado renuncie a su cargo o que la otra parte acepte la recusación, corresponderá al Presidente de Bitartu la resolución sobre la misma en diez días desde la recepción de Bitartu de la recusación. Si no prosperase la recusación planteada, la parte recusante podrá, en su caso, hacer valer la recusación al impugnar el laudo.

No pueden ser árbitros en ningún caso quienes ostenten la condición de jueces, magistrados o fiscales en activo, o ejerzan funciones públicas retribuidas por arancel ni los que no hayan cumplido totalmente su responsabilidad, en el supuesto de que la misma hubiera sido declarada judicialmente por el desempeño anterior de funciones arbitrales.

La función de los árbitros será resolver el conflicto a través de un laudo arbitral que se dictará por escrito y expresará, al menos, las cir- 
cunstancias personales de los árbitros y de las partes, el lugar en que se dicta, la cuestión sometida a arbitraje, una sucinta relación de las pruebas practicadas, alegaciones de las partes y decisión arbitral, así como los gastos, y la imputación de los mismos, causados en el arbitraje.

Sea el arbitraje de derecho o de equidad, tendrá que ser motivado, a menos que se trate de un laudo pronunciado en los términos convenidos por las partes. Además, deberá ser firmado por los árbitros. En el caso del Colegio Arbitral, el árbitro que no estuviera de acuerdo con el laudo, podrá hacer constar su parecer discrepante.

Deberán dictarlo en el plazo máximo de seis meses desde la fecha de presentación de la contestación a la demanda o de la expiración del plazo para presentarla. No obstante lo anterior, quedará prorrogado en los casos de suspensión temporal.

Para su designación, el Pleno del Consejo Superior de Cooperativas de Euskadi confeccionará una lista de árbitros compuesta por personas de notorio prestigio y competencia en el conocimiento de la materia cooperativa y luego el Presidente de Bitartu designará el árbitro o árbitros que crea idóneos y cumplan los requisitos legales. No obstante, las partes podrán designarlos de mutuo acuerdo siempre y cuando cumplan los requisitos. Una vez nombrado el árbitro debe aceptar. Por el hecho de la aceptación se compromete y obliga a resolver el arbitraje de conformidad con la presente normativa.

En caso de que sean tres árbitros será un Colegio Arbitral que podrá delegar en cualquiera de sus miembros la realización de cualquier acto de tramitación del procedimiento. Sin perjuicio de lo anterior, el Presidente podrá decidir por sí solo cuestiones de ordenación, tramitación e impulso del procedimiento. El Colegio Arbitral adoptará sus acuerdos por mayoría de sus miembros.

Tanto los árbitros como Bitartu podrán exigir a las partes las provisiones de fondos que estimen necesarias para atender a los honorarios no cubiertos por el Consejo Superior de Cooperativas de Euskadi así como los gastos que pudieran derivarse de la administración del arbitraje. A falta de provisión de fondos, los árbitros podrán suspender o dar por concluidas las actuaciones si alguna de las partes no hubiera realizado tal provisión en el plazo, pero lo deberán comunicar previamente a todas las partes personadas.

El procedimiento del arbitraje comienza cuando alguna de las partes lo solicita por escrito ante el Consejo Superior de Cooperativas de 
Euskadi y será el Presidente de Bitartu quien lo admita a trámite mediante una resolución y proceda a designar a los árbitros. Se considerará como fecha de inicio del arbitraje la fecha de recepción de la notificación de admisión a trámite. La parte demandante en 15 días deberá formular por escrito su demanda y proposición de prueba y se enviará al demandado para que también en 15 días formule la contestación y proposición de prueba y se remitirá al demandante. A continuación las partes presentarán todos los documentos que crean necesarios.

Los árbitros podrán decidir sobre la realización o no de las pruebas propuestas, procediendo a la práctica de las que estimen pertinentes, útiles y admisibles en derecho.

Además podrán realizar las que estimen convenientes y podrán solicitar la ayuda del juez de primera instancia. Tienen 30 días para practicarlas y su resultado se deberá comunicar a las partes. Una vez finalizado el período de pruebas las partes en 15 días deben presentar sus conclusiones. Eso sí, una vez que el árbitro los conoce puede utilizar nuevas pruebas y esta vez las partes deberán presentar las nuevas conclusiones en 5 días.

Tras las conclusiones, el árbitro dictará un laudo aunque ésta no es la única forma de terminar el procedimiento sino que si durante las actuaciones arbitrales las partes llegan a un acuerdo que ponga fin total o parcialmente a la controversia, los árbitros darán por terminadas las actuaciones con respecto a los puntos acordados y, si ambas partes lo solicitan y los árbitros no aprecian motivo para oponerse, harán constar ese acuerdo en forma de laudo, en los términos convenidos por las partes. Dicho laudo tendrá la misma eficacia que cualquier otro laudo dictado sobre el fondo del litigio. También ordenarán la terminación de las actuaciones cuando:

a) El demandante desista de su demanda, a menos que el demandado se oponga a ello y los árbitros le reconozcan un interés legítimo en obtener una solución definitiva del litigio.

b) Las partes acuerden dar por terminadas las actuaciones.

c) Los árbitros comprueben que la continuación de las actuaciones resulta innecesaria o imposible.

Los árbitros notificarán el laudo a las partes, a través de la Secretaría de Bitartu, mediante entrega a cada una de ellas de un ejemplar firmado y dentro del plazo establecido. De oficio, o a instancia de cualquiera de las partes y a su costa, podrán decidir la protocolización del laudo antes de su notificación. 
Una vez que han acabado las actuaciones, cesará la obligación de los árbitros de conservar la documentación del procedimiento, debiendo remitirla para su archivo al secretario de Bitartu. Dentro del plazo de dos meses cualquiera de las partes podrá solicitar a Bitartu que le remita los documentos presentados por ella. Bitartu accederá a la solicitud siempre que el solicitante asuma los gastos correspondientes al envío.

En los diez días siguientes a la notificación del laudo, cualquiera de las partes podrá solicitar a los árbitros:

a) La corrección de cualquier error de cálculo, de copia, tipográfico o de naturaleza similar.

b) La aclaración de un punto o de una parte concreta del laudo.

c) El complemento del laudo respecto de peticiones formuladas y no resueltas en él.

Previa audiencia a las partes, los árbitros resolverán sobre las solicitudes de corrección de errores y de aclaración en el plazo de diez días y sobre la solicitud de complemento en el plazo de veinte días. Podrán proceder de oficio a la corrección de errores.

El laudo sólo podrá ser anulado cuando la parte que solicita la anulación alegue y pruebe:

a) Que el convenio arbitral no existe o no es válido.

b) Que no le ha sido debidamente notificada la designación de los árbitros o las actuaciones arbitrales o no ha podido, por cualquier otra razón, hacer valer sus derechos.

c) Que los árbitros han resuelto sobre cuestiones no sometidas a su decisión.

d) Que la designación de los árbitros, o el procedimiento arbitral, no se han ajustado al acuerdo entre las partes, salvo que dicho acuerdo fuera contrario a una norma imperativa de la Ley 60/2004, de Arbitraje, o, a falta de dicho acuerdo, que no se han ajustado a la citada Ley.

e) Que los árbitros han resuelto sobre cuestiones no susceptibles de arbitraje.

f) Que el laudo es contrario al orden público.

El laudo firme produce efectos de cosa juzgada y frente a él sólo cabrá la revisión conforme a lo establecido en la Ley de Enjuiciamiento Civil para las sentencias firmes. 
Todas y cada una de las partes intervinientes en este proceso aceptan y acatan el laudo que resulte del mismo obligándose a su cumplimiento.

La administración del arbitraje del Consejo Superior de Cooperativas de Euskadi será gratuita hasta el importe que acuerde anualmente el Pleno del Consejo Superior. Dicho importe, así como sus modificaciones, se publicarán en el Boletín Oficial del País Vasco para su general conocimiento. Todo lo que no resultare gratuito deberá ser abonado por las partes de conformidad con lo establecido en el laudo.

El laudo también señalará los gastos debidamente justificados que no correspondan a la propia actuación arbitral y, en su caso, los derivados de notificaciones, los que origine la práctica de las pruebas y cualquier otro que pudiera existir. Asimismo, el laudo se podrá pronunciar sobre los honorarios de los representantes de las partes si los hubiere. En todo caso, si las partes tuvieran que realizar cualquier tipo de pago, lo harán directamente a Bitartu.

Cada parte deberá satisfacer los gastos efectuados a su instancia y los que sean comunes por partes iguales, a no ser que los árbitros apreciasen mala fe o temeridad en alguna de ellas. En este último caso, el reparto de los gastos se determinará, a criterio de los árbitros, en el laudo.

En caso de desestimiento del procedimiento, la resolución que dicte Bitartu como consecuencia de dicho acuerdo determinará el reparto y en el supuesto de suspensión el reparto tendrá carácter provisional mientras no tenga lugar la terminación del procedimiento por laudo, que podrá establecer un reparto definitivo igual o diferente al provisional, salvo que exista acuerdo mutuo entre las partes.

Los honorarios de los árbitros serán los que así determine el Pleno del Consejo Superior de Cooperativas de Euskadi.

\section{La Mediación}

\section{Los Agentes Mediadores del Comercio}

La figura del agente mediador tiene unos caracteres peculiares que lo diferencian de otras profesiones similares. Actúa en el ejercicio de una función pública combinando estatuto profesional con otro de autoridad pública. La razón de su mediación proviene de la constante relación con inversores y sociedades de capital y de la independencia 
del agente que provoca un asesoramiento imparcial y objetivo. Su intervención garantiza jurídica y económicamente la transmisión y suscripción de valores mobiliarios, además de colaborar en el asesoramiento, gestión y administración de dichas transmisiones.

Además, el agente tiene una misión complementaria de legislar junto con la Administración Pública ya que su continua relación con el movimiento y transacciones de las empresas trae consigo que el agente aplique medios propios a cada caso concreto, lo que permite un auxilio de los textos caducos que no traen esa ayuda. La Administración Tributaria también se ve favorecida por su intervención puesto que éste vela por el exacto cumplimiento de las normas fiscales en materia de tráfico de empresas y transmisiones patrimoniales.

En general, el mediador cuida del cumplimiento de todas las disposiciones administrativas que se promulgan, lo más importante es que gracias a su intervención actualiza los preceptos día a día y hace posible su aplicación. La confrontación del derecho con la práctica económicocomercial trae consigo que el mediador o agente, además de aplicar las leyes y reglamentos, desarrolla paralelamente a su actividad una importante labor para tratar de conseguir la reforma jurídica necesaria.

\section{El Contrato de Mediación}

Una posible definición puede ser la que nos da el profesor Broseta como «aquél por el que una parte se obliga frente a otra u otras, sin relación de dependencia ni de representación, a desplegar una actividad dirigida a procurar la conclusión de un contrato». A través de la mediación, los técnicos de las Cámaras intentan aproximar las partes en conflicto para que sean ellas quienes encuentren la solución del mismo. Los técnicos crean de nuevo el diálogo entre las partes, restableciendo así las relaciones mercantiles y facilitando la continuidad de futuras relaciones comerciales. Mediante la mediación, serán las partes quienes, de mutuo acuerdo y de buena fe, logren la solución del caso planteado, no pudiendo la Cámara en ningún caso imponer la solución ni obligar a las partes a su cumplimiento.

Las notas características de un contrato así son varias:

1. El mediador tan sólo se compromete a desplegar la actividad naturalmente necesaria para promover la conclusión del contrato, pero no se obliga a obtener el resultado deseado, el cual escapa a sus posibilidades. Está claro que un mediador hará 
todo lo posible por solucionar el conflicto, pero no siempre garantiza que se vaya a lograr.

2. ${ }^{\circ}$ El mediador actúa con absoluta independencia, sin subordinación alguna a quien le formula el encargo. Esto garantiza que el mediador pueda actuar con total libertad sin estar condicionado a la hora de tomar decisiones.

3. El mediador se limita a buscar y a aproximar a las partes, pero no contrata en nombre de sus clientes cuyo nombre suele ocultar en las gestiones preliminares en virtud de un deber de secreto que caracteriza su función. Este secreto es el denominado secreto profesional, éste es un deber que suelen tener muchos profesionales a la hora de ejercer sus funciones y que se basa en garantizar la privacidad de los datos de sus clientes que obtienen como resultado de realizar su profesión. Puede ser interrumpido en casos excepcionales como son el interés público o la seguridad ciudadana.

4. ${ }^{\circ}$ La actividad del mediador debe retribuirse cuando se obtenga el resultado previsto y deseado. Esta es una medida que garantiza que el agente despliegue todas sus virtudes y conocimientos en el mayor grado posible para que no vea todo su trabajo sin recompensar y, de este modo, se esfuerce al máximo.

Garrigues define la mediación como «aquélla en que una de las partes se obliga a abonar a otra, llamada mediador, una remuneración por el hecho de indicar la oportunidad de celebrar un contrato o por el hecho de conseguir por su propia actividad esta celebración».

Este contrato puede tener analogías con otros contratos como el de comisión y agencia. Respecto a ellos se diferencia, entre otras cosas, porque el mediador tan sólo promueve o busca clientes, pero nunca contrata con ellos por cuenta de su mandante. Además reciben encargos aislados o individuales por lo que su duración y ejecución es instantánea. Por otro lado no soportan exclusividad alguna sobre su cliente ni se reconoce la revocabilidad del encargo. La nota común a todos ellos es que gestionan intereses ajenos.

\section{Regulación: Título V}

Artículo 55.-La mediación ante Bitartu.

Toda controversia que se suscite en el ámbito del artículo 3 del presente Reglamento podrá someterse, previo acuerdo de las partes, a la mediación de Bitartu. 


\section{Artículo 56.-El mediador}

Uno.- El mediador procurará el acuerdo entre las partes. No tendrá poder de decisión, ni podrá imponer solución alguna a las partes.

Dos.-El Pleno del Consejo Superior de Cooperativas de Euskadi confeccionará la lista de mediadores.

Tres.-El mediador no dará testimonio sobre la controversia sometida a mediación en juicios, arbitrajes u otros procedimientos que se susciten.

Cuatro.- La abstención, recusación y sustitución del mediador se regirá por lo establecido en los artículos 30 y 31 del presente Reglamento.

\section{Artículo 57.-El procedimiento de mediación}

Uno.- La solicitud de mediación se presentará por escrito por alguna de las partes en la sede de Bitartu. En todo caso, se redactará en los términos expresados en el artículo 33 del presente Reglamento.

Dos.-El Presidente de Bitartu, mediante resolución, admitirá a trámite la solicitud de mediación y designará mediador. En ausencia de sometimiento a mediación, dará traslado de la solicitud a la parte contraria para que en el plazo de diez días comunique, en su caso, por escrito su aceptación y presente sus alegaciones. Si no se contestara Bitartu archivará las actuaciones.

Tres.-Aceptada la mediación por la parte contraria, el Secretario comunicará al mediador su designación para su aceptación. El mediador comunicará a Bitartu su aceptación expresa y a las partes su designación, en el plazo de diez días.

Cuatro.-La actividad del mediador comenzará inmediatamente después de su designación y tendrá una duración máxima de dos meses, prorrogables a petición expresa de las partes.

Cinco.-El mediador actuará con absoluta imparcialidad y neutralidad, salvaguardando los principios de igualdad y contradicción de las partes. Así mismo, garantizará el derecho de audiencia de todas las partes, la confidencialidad de la causa y privacidad de la documentación e información aportada por las partes.

Seis.-Las partes actuarán de buena fe y podrán estar representadas o asistidas en el procedimiento por personas debidamente facultadas, siempre y cuando el mediador tenga constancia previa de tal circunstancia.

Artículo 58.-Fin de la mediación

Uno.-El procedimiento de mediación finalizará por:

a) El acuerdo de partes.

b) El desestimiento expreso de cualquiera de las partes. 
c) La decisión motivada del mediador.

d) La finalización del plazo establecido para la mediación, y que no haya sido prorrogado.

Dos.-El mediador notificará por escrito a Bitartu la finalización de la mediación, indicando si el acuerdo, en el caso de que lo hubiera, fue total o parcial, la fecha, y el lugar donde tuvo lugar la vista, debiéndose enviar copia a las partes de dicha notificación.

Tres.-Finalizada la mediación, el mediador y Bitartu restituirán a petición de las partes, y a su costa, todo documento escrito que hayan presentado para el desarrollo de la mediación.

Cuatro.-La administración de la mediación del Consejo Superior de Cooperativas de Euskadi será gratuita hasta el importe que se señale anualmente en el Pleno del Consejo Superior y en los mismos términos regulados en el artículo 51 del presente Reglamento para la administración del arbitraje.

\section{La función mediadora del Agente Mediador}

Vicente y Gella definen el mediador como «el comerciante que se ocupa profesionalmente de facilitar la conclusión de negocios mercantiles y el carácter de comerciante le alcanza como consecuencia de realizar en nombre propio actos de mediación cuya naturaleza comercial es indiscutible».

A lo largo de la historia siempre se han encontrado profesionales que ejercían esta labor, en un comienzo sólo se encargaban de aproximar a quienes deseaban estipular un contrato determinado o bien de realizar dicho contrato por cuenta del cliente que les formulaba el encargo. Más adelante pasaron a dotar de autenticidad a la contratación mercantil en la que intervenían, siempre que para ello estuvieran adscritos a un Colegio Público. Esto último es lo que recoge nuestro Código de Comercio en los artículos 88 y siguientes.

Artículo 88.-Estarán sujetos a las Leyes mercantiles como Agentes Mediadores del comercio:

- Los Agentes de Cambio y Bolsa.

- Los Corredores de Comercio.

- Los Corredores Intérpretes de Buques.

Los Agentes Mediadores son verdaderos empresarios mercantiles cuya actividad consiste, fundamentalmente, en gestionar intereses ajenos en la contratación mercantil. La mediación a la que hace referencia el Código es un concepto amplio de la misma, al no regular nuestro ordenamiento el contrato de mediación, el Código ha 
aplicado el término en un sentido usual, genérico, desprovisto del carácter jurídico que tiene en otras legislaciones que han regulado la figura. Esto es algo poco usual, ya que el Código se caracteriza por su buena redacción y precisión en todos sus conceptos.

La actividad de mediadores puede ser de dos clases, o bien la propia de los comisionistas que contratan por cuenta de sus comitentes, que es la que suele predominar, o bien la de puros mediadores que se limiten a aproximar a las partes. En la primera de las dos facetas el agente es parte contratante en el negocio para el que fue convenida la comisión, en la segunda el agente no es parte contratante en el negocio para el cual fue convenida y realizada la mediación, cuyo negocio es celebrado directamente por los interesados y en los que el agente podrá o no actuar finalmente como fedatario público.

\section{Aspectos Prácticos}

La función mediadora impone al agente dos obligaciones fundamentales, contenidas en el Código de Comercio:

1. La de proponer con exactitud, precisión y claridad los negocios por cuenta de sus comitentes, absteniéndose de hacer supuestos que induzcan a error a los contratantes.

2. ${ }^{\circ}$ El deber de guardar secreto, que antes mencionamos, en lo concerniente a las negociaciones que se hagan, no revelando el nombre de las personas que se las encargan, a menos que exijan lo contrario la Ley o la naturaleza de las operaciones o los interesados consientan en que sus nombres sean conocidos.

La mediación mercantil colegiada tiene un amplio futuro a desarrollar, por ejemplo, en el mercado de valores. En esta función conviene destacar que el ámbito de la actuación mediado no está limitado y puede ejercerse en toda clase de negocios o actividades mercantiles. La idoneidad en la elección del agente es otro punto a destacar y para ello se necesita el carácter de imparcialidad, que sea un intermediario oficial, especializado, organizado y responsable. Todo ello asegura la mejor práctica de la profesión del mediador porque dota de seguridad y preparación al sistema.

\section{LA INTERVEnCIÓN del Agente MediAdoR: ConCEPTO Y eFICACIA JURÍDICA}

La función del Agente Mediador tiene dos aspectos:

1. Mediar en el concierto de las operaciones, al que el Código le da plena libertad para ejercitarlo. 
2. Dación de fe para cuyo ejercicio es necesaria la condición de Agente de Cambio y Bolsa, Corredor de Comercio o Corredor Intérprete de buques.

La mediación consiste en que una de las partes se obliga a abonar a la otra, llamada mediador, una remuneración por el hecho de indicar la oportunidad de celebrar un contrato o por el hecho de conseguir por su propia actividad esta celebración.

A menudo, la mediación es una de las actividades fundamentales que se inserta en la intervención en sentido amplio del mediador. Este nunca puede actuar de oficio, tiene que actuar siempre a requerimiento o instancia de las partes contratantes, o, al menos, de una de ellas, en los negocios bilaterales o plurilaterales, o del interesado cuando haya de dar fe de un hecho o acto de naturaleza no contractual. No basta con que sea un acto $u$ operación mercantil para que sea susceptible de intervención por parte del mediador. El artículo 93 del Código de Comercio exige, además, que tales actos u operaciones mercantiles estén comprendidos en su oficio, en el oficio de Agente de Cambio y Bolsa, de Corredor de Comercio o de Corredor Intérprete de buques, de acuerdo con el artículo 88 del mismo cuerpo legal.

Así pues, podemos concluir que las operaciones que no estén reservadas a la intervención de otros fedatarios con carácter exclusivo, que es donde se halla el límite de la competencia objetiva del Mediador, en lo que se refiere a su intervención fedataria, son susceptibles de ser intervenidas por el Agente Mediador.

\section{Competencia objetiva atílica de los Agentes Mediadores \\ OfICIALES}

Contratos de cuentas corrientes, contrato de hospedaje, opción de compra, contrato estimatorio, contrato de edición, reconocimiento de deuda, contrato de suministro, contrato de leasing, contrato de factoring, contrato de corretaje, contrato de agencia, contrato de concesión o distribución, contratos publicitarios, otorgamiento de poderes mercantiles, autorización de actas aplicables al comercio, que son susceptibles de ser autorizadas por fedatario mercantil, contrato de anuncio y constitución de «clubs» de inversión, contratos «merchandsing», arbitraje comercial, etc. 


\section{La Conciliación}

En términos legales, la conciliación es un proceso especial cuya finalidad es eliminar la incoación de un proceso principal tratando de llegar a un acuerdo entre dos partes, los futuros litigantes, con la mediación de un tercero independiente como medio para evitar el litigio. Esta definición se extrae del diccionario de «Economía y negocios» juntamente con el «Diccionario de Derecho» de Luis Ribó Durán.

En términos cooperativos la conciliación supone, en Título IV del Reglamento de Cooperativas del Consejo Superior de Cooperativas de Euskadi, lo siguiente:

\section{Artículo 54.—La conciliación ante Bitartu}

Uno.-Cualquier controversia de las contempladas en el artículo 3 del presente Reglamento podrá someterse, previo acuerdo de las partes, a la conciliación ante el Secretario de Bitartu, quien podrá delegar la realización de la misma en el Letrado Asesor del Consejo Superior de Cooperativas de Euskadi.

Dos.-Para ello, las partes interesadas serán citadas a una comparecencia de conciliación, al final de la cual, si hubiera avenencia, se formalizará el acuerdo en un documento que ambas partes suscribirán firmando, en el plazo máximo de cinco días, los términos del convenio y que será rubricado a los solos efectos testimoniales por el conciliador de Bitartu.

Tres.-En el caso de no avenencia en la comparecencia de conciliación, el conciliador de Bitartu levantará un acta que, firmada por él, recoja este extremo.

Cuatro.-Ambas partes, de común acuerdo, podrán suspender la conciliación por un plazo no superior a diez días a la espera de que el conciliador de Bitartu les presente una propuesta formal, que cada uno aceptará o rechazará libremente.

Quinto.-En cualquier caso, la celebración de una conciliación ante Bitartu no impide, caso de no finalizar con avenencia, que las partes puedan acudir a otro de los procedimientos regulados en este Reglamento.

La conciliación supone, por tanto, un medio de resolución de conflictos, previo a la vía judicial. Es un medio con poca extensión en el tiempo que se desarrolla ante el Secretario de Bitartu, quien podrá delegar la realización de la misma en el Letrado Asesor del Consejo Superior de Cooperativas de Euskadi. 
El acuerdo al que lleguen las partes, en su caso, será firmado por ambas y testimoniado por el Secretario de Bitartu. El citado acuerdo es de obligado cumplimiento entre las partes. Creemos que se trata de un documento público que puede tener incluso fuerza ejecutiva. 